Article

\title{
Phytochemical Quantification and the In Vitro Acetylcholinesterase Inhibitory Activity of Phellodendron chinense and Its Components
}

\author{
Yu Jin Kim ${ }^{1,2,+}$, Hye-Sun Lim ${ }^{1, \dagger}$, Yoonju Kim ${ }^{1}$, Jun Lee ${ }^{1,3}$, Bu-Yeo Kim ${ }^{1}$ and Soo-Jin Jeong ${ }^{1,3, *}$ \\ 1 Herbal Medicine Research Division, Korea Institute of Oriental Medicine, Daejeon 34054, Korea; \\ jinjin0228@kiom.re.kr (Y.J.K.); qp1015@kiom.re.kr (H.-S.L.); yoonjukim@kiom.re.kr (Y.K.); \\ junlee@kiom.re.kr (J.L.); buykim@kiom.re.kr (B.-Y.K.) \\ 2 College of Pharmacy, Chungnam National University, Daejeon 34134, Korea \\ 3 Korean Medicine of Life Science, University of Science \& Technology, Daejeon 34113, Korea \\ * Correspondence: sjijeong@kiom.re.kr; Tel.: +82-42-868-9651 \\ + These authors contributed equally to this work.
}

Academic Editor: Derek J. McPhee

Received: 10 April 2017; Accepted: 30 May 2017; Published: 2 June 2017

\begin{abstract}
The dried bark of Phellodendron chinense has been used as a traditional herbal medicine to remove damp heat, relieve consumptive fever, and cure dysentery and diarrhea. In the present study, we performed quantitative analyses of the two components of $P$. chinense, phellodendrine and berberine, using high-performance liquid chromatography. A 70\% ethanol extract of $P$. chinense was prepared and the two components were separated on a C-18 analytical column using a gradient solvent system of acetonitrile and $0.1 \%(v / v)$ aqueous trifluoroacetic acid. The ultraviolet wavelength used for detection was $200 \mathrm{~nm}$ for phellodendrine and $226 \mathrm{~nm}$ for berberine. The analytical method established here showed high linearity (correlation coefficient, $\geq 0.9991$ ). The amount of phellodendrine and berberine used was $22.255 \pm 0.123 \mathrm{mg} / \mathrm{g}$ and $269.651 \pm 1.257 \mathrm{mg} / \mathrm{g}$, respectively. Moreover, we performed an in vitro acetylcholinesterase (AChE) activity assay and an amyloid- $\beta$ aggregation test to examine the biological properties of phellodendrine and berberine as therapeutic drugs for Alzheimer's disease. Phellodendrine and berberine inhibited AChE activity in a dose-dependent manner $\left(\mathrm{IC}_{50}=36.51\right.$ and $0.44 \mu \mathrm{M}$, respectively). In contrast, neither phellodendrine nor berberine had an effect on amyloid- $\beta$ aggregation. The $P$. chinense extract and phellodendrine, but not berberine, exhibited antioxidant activity by increasing radical scavenging activity. Moreover, $P$. chinense demonstrated a neuroprotective effect in hydrogen peroxide-treated HT22 hippocampal cells. Overall, our findings suggest that $P$. chinense has potential as an anti-Alzheimer's agent via the suppression of the enzymatic activity of acetylcholinesterase and the stimulation of antioxidant activity.
\end{abstract}

Keywords: Phellodendron chinense; phellodendrine; quantitative analysis; neuroprotection

\section{Introduction}

Alzheimer's disease is a type of dementia that is associated with a loss of memory and other intellectual abilities that is sufficiently serious to interfere with daily life. Alzheimer's disease is the most common form of dementia and accounts for about $60-70 \%$ of all dementia cases $[1,2]$. Risk factors for Alzheimer's disease include aging and genetic problems, with several genes being involved [3]. Although Alzheimer's disease is the seventh leading cause of death worldwide [4], no therapeutic method has been developed. Currently, acetylcholinesterase (AChE) inhibition and amyloid- $\beta$ aggregation are considered as the two pivotal targets for developing anti-Alzheimer's disease drug(s) [5,6]. 
Phellodendron chinense (P. chinense) is a medicinal plant in the genus Phellodendron, traditionally used to treat damp heat, relieve consumptive fever, and cure dysentery and diarrhea $[7,8]$. $P$. chinense has also been medicinally used to quench fire, counteract toxicity, and cure heat accumulation in the intestines and stomach. In addition, the potential of $P$. chinense was reported as an immune-modulator [9]. Thus, $P$. chinense is a major composition of various herbal formulae such as Hwanglyeonhaedok-tang and Dangguiyukhwang-tang. Of interest, recent scientific reports determined the biological activities of $P$. chinense and its active components, which include anticancer [10,11], anti-inflammation [12], antidiabetes (and its complications) [13], and antialgal [14] activities, as well as neuroprotection [15]. However, Xian et al. [15] described the neuroprotective effect of $P$. chinense using PC12 cells derived from pheochromocytoma of the rat adrenal medulla, and not neuronal cells. They did not examine whether the components of $P$. chinense have the same biological activity. In the present study, we investigated the inhibitory effect of $P$. chinense and its two standard components on the key biomarkers of Alzheimer's disease and neuronal cell damage using HT22 murine hippocampal cells. We also performed a high-performance liquid chromatography (HPLC) analysis to obtain quantitative information regarding the two components of $P$. chinense.

\section{Results}

\subsection{Optimization of HPLC Separation}

We used HPLC for the separation of the two standard components of the $70 \%$ ethanol extract of $P$. chinense. The established condition of the mobile phase is shown in Table 1 . In the detector wavelength ranging from 190 to $400 \mathrm{~nm}$, ultraviolet (UV) recordings were performed at a wavelength of $200 \mathrm{~nm}$ for phellodendrine (Figure 1A) and $226 \mathrm{~nm}$ for berberine (Figure 1B). Using this HPLC method, the two standard components were resolved within $35 \mathrm{~min}$. The retention times of phellodendrine and berberine were $21.36 \mathrm{~min}$ and $34.14 \mathrm{~min}$, respectively. The HPLC chromatograms of the $70 \%$ ethanol extract of $P$. chinense and the standard mixture are shown in Figure 2.

Table 1. Condition of mobile phase for HPLC analysis.

\begin{tabular}{cccc}
\hline \multirow{2}{*}{ Time (min) } & \multirow{2}{*}{ Flow Rate (mL/min) } & \multicolumn{3}{c}{ Mobile Phase } \\
\cline { 3 - 4 } & & $\mathbf{0 . 1 \%}$ Trifluoroacetic Acidin Water (\%) & Acetonitrile (\%) \\
\hline 0 & 1.0 & 100 & 0 \\
40 & 1.0 & 55 & 45 \\
45 & 1.0 & 0 & 100 \\
52 & 1.0 & 0 & 100 \\
\hline
\end{tabular}

(A)

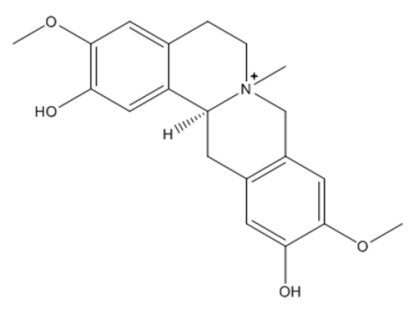

Phellodendrine
(B)

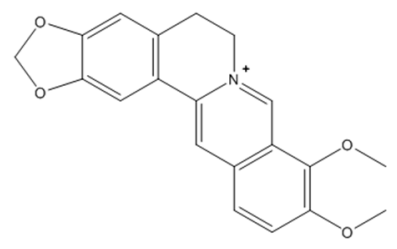

Berberine

Figure 1. Chemical structures of the two marker compounds of $P$. chinense: (A) phellodendrine and (B) berberine. 


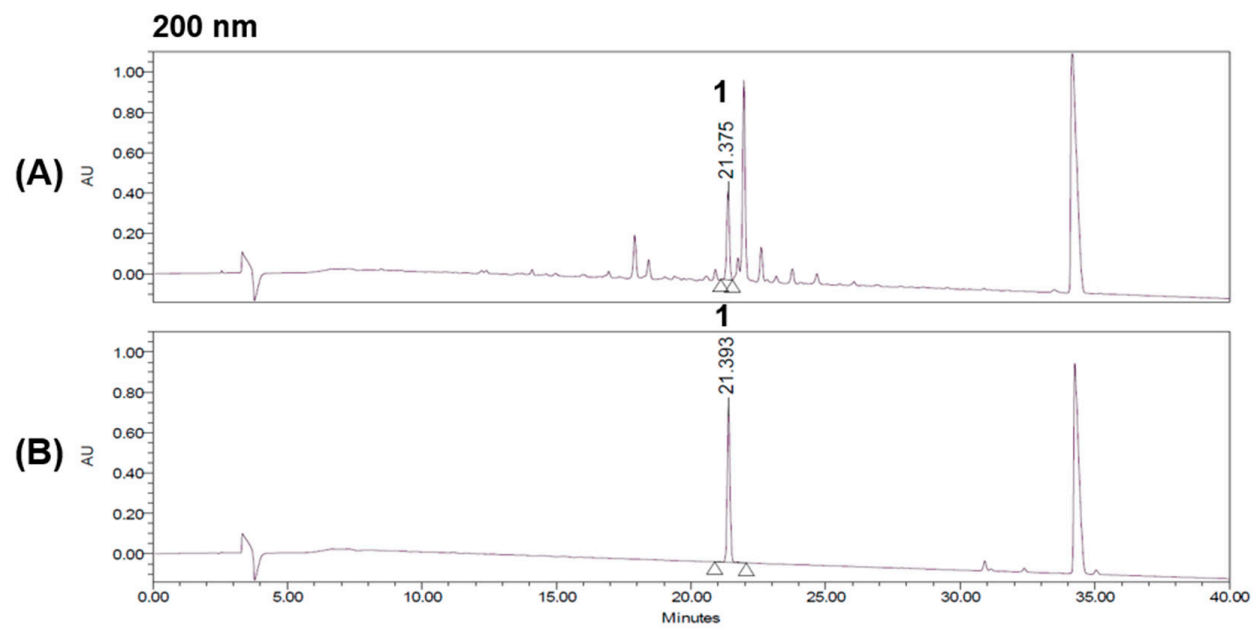

$226 \mathrm{~nm}$

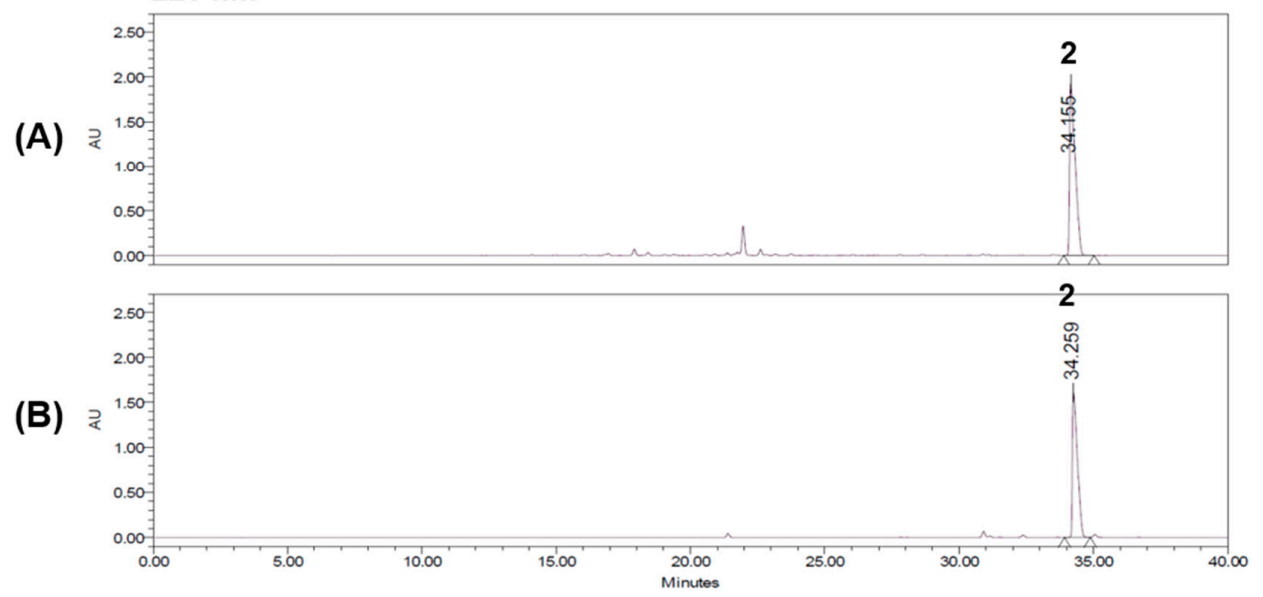

Figure 2. HPLC chromatograms of the 70\% ethanol extract of the bark of $P$. chinense (A) and a standard mixture (B) at $200 \mathrm{~nm}$ and $226 \mathrm{~nm}$. Phellodendrine (1) and berberine (2).

\subsection{Linearity, Limit of Detection (LOD), and Limit of Quantitation (LOQ)}

The linear relationships between the peak areas $(y)$ and concentrations $(x, \mu \mathrm{g} / \mathrm{mL})$ of the components are expressed by the regression equations $(y=a x+b)$ given in Table 2 . The linearity of the analytical method established here was evaluated based on the correlation coefficient $\left(r^{2}\right)$ value of the calibration curves of each component. The calibration curves showed linearity, with $r^{2}$ values $\geq 0.9991$ over the concentration ranges of $12.5-200 \mu \mathrm{g} / \mathrm{mL}$ for phellodendrine and $62.5-1000 \mu \mathrm{g} / \mathrm{mL}$ for berberine. The LOD and LOQ for the two standard components, phellodendrine and berberine, were 0.301 and $1.555 \mu \mathrm{g} / \mathrm{mL}$ and 0.911 and $4.712 \mu \mathrm{g} / \mathrm{mL}$, respectively.

Table 2. Linear range, regression equation, correlation coefficients, limits of detection (LODs), and limits of quantitation (LOQs) for compounds.

\begin{tabular}{|c|c|c|c|c|c|c|}
\hline \multirow{2}{*}{ Compound } & \multirow{2}{*}{$\begin{array}{c}\text { Linear Range } \\
(\mu \mathrm{g} / \mathrm{mL})\end{array}$} & \multicolumn{2}{|c|}{ Regression Equation $(y=\mathbf{a} x+\mathbf{b})^{(a)}$} & \multirow{2}{*}{$\begin{array}{c}\text { Correlation } \\
\text { Coefficient }\left(r^{2}\right)\end{array}$} & \multirow{2}{*}{$\begin{array}{l}\operatorname{LOD}^{(b)} \\
(\mu g / m L)\end{array}$} & \multirow{2}{*}{$\begin{array}{l}\mathrm{LOQ}^{(\mathrm{c})} \\
(\mu \mathrm{g} / \mathrm{mL})\end{array}$} \\
\hline & & Slope ${ }^{(a)}$ & Intercept $^{(b)}$ & & & \\
\hline Phellodendrine & $12.5-200$ & 52,064 & 222,327 & 0.9991 & 0.301 & 0.911 \\
\hline Berberine & $62.5-1000$ & 40,183 & 434,513 & 0.9998 & 1.555 & 4.712 \\
\hline
\end{tabular}

(a) $y=\mathrm{a} x+\mathrm{b}, y$ means peak area and $x$ means concentration $(\mu \mathrm{g} / \mathrm{mL}){ }^{(\mathrm{b})}$ LOD: $3.3 \times($ standard deviation (SD) of the response/slope of the calibration curve); ${ }^{(c)}$ LOQ: $10 \times(\mathrm{SD}$ of the response/slope of the calibration curve). 


\subsection{Determination of the Two Standard Components of P. chinense}

The HPLC analytical method established here was applied to the simultaneous quantification of the two components of $P$. chinense. The amount of the two standard components is shown in Table 3. Of the two components, berberine $(269.651 \mathrm{mg} / \mathrm{g})$ was the most abundant compared with phellodendrine $(22.255 \mathrm{mg} / \mathrm{g})$ in the bark of $P$. chinense.

Table 3. The content of marker compounds in P. chinense.

\begin{tabular}{cc}
\hline Compound & Content $(\mathrm{mg} / \mathrm{g})$ \\
\hline Phellodendrine & $22.255 \pm 0.123$ \\
Berberine & $269.651 \pm 1.257$ \\
\hline
\end{tabular}

\subsection{Inhibitory Effects of the P. chinense Extract and Its Standard Components on AChE Activity}

To determine the biological activity of the P. chinense extract, its effects on the activation of AChE and the aggregation of amyloid- $\beta$, both of which are key events in Alzheimer's disease, were assessed. The $P$. chinense extract dramatically inhibited AChE activity at $100 \mu \mathrm{g} / \mathrm{mL}$. In contrast, no significant effect was observed on amyloid- $\beta$ aggregation (Table 4). Inhibition of AChE activity by the P. chinense extract was further confirmed at lower concentrations, including 12.5, 25 or $50 \mu \mathrm{g} / \mathrm{mL}$. As shown in Figure 3A, the P. chinense extract markedly decreased the activity of AChE, even at $12.5 \mu \mathrm{g} / \mathrm{mL}$. Additional assays were performed to examine whether the standard components of $P$. chinense affect AChE activity. Both components increased the inhibition of AChE activity in a dose-dependent manner (Figure 3B,C). All experiments were carried out at ranges of the non-toxic concentrations based on results of the cytotoxicity assays against neuronal cells (data not shown).

Table 4. Inhibitory activity of $P$. chinense on in vitro acetylcholinesterase (AChE) activity and amyloid- $\beta$ aggregation (at $100 \mu \mathrm{g} / \mathrm{mL}$ ).

\begin{tabular}{cc}
\hline Inhibition of AChE Activity (\%) & Inhibition of Amyloid- $\beta$ Aggregation (\%) \\
\hline $98.92 \pm 0$ & $-7.54 \pm 5.74$ \\
\hline
\end{tabular}

(A)

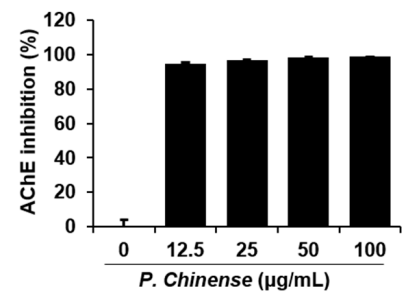

(B)

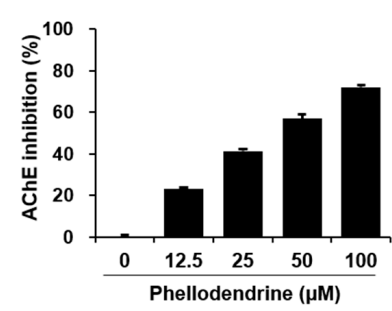

(C)

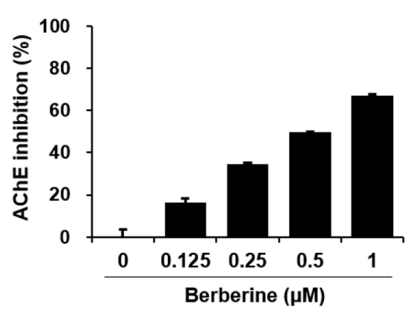

Figure 3. Effects of an ethanol extract of $P$. chinense and its components on acetylcholinesterase (AChE) activity. The AChE activity assay was performed using a modified Ellman's colorimetric method. The enzymatic reaction was performed by incubating the mixture of AChE solution and various concentrations of the P. chinense extract (A); phellodendrine (B); and berberine (C) for $1 \mathrm{~h}$ at room temperature. The absorbance was measured at $412 \mathrm{~nm}$ using an Epoch microplate spectrophotometer (Bio-Tek Instruments, Winooski, VT, USA). Each value is presented as the mean $\pm \operatorname{SEM}(n=3)$. 


\subsection{Antioxidant Activity of the P. chinense Extract and Its Standard Components}

The antioxidant effect of the $P$. chinense extract was determined by measuring the $2,2^{\prime}$-azinobis(3-ethylbenzothiazoline-6-sulphonic acid) (ABTS) radical scavenging activities. As shown in Figure 4A, the $P$. chinense extract increased the radical scavenging activity of ABTS in a dose-dependent manner. Of its two standard components, phellodendrine, but not berberine, enhanced the ABTS radical scavenging activity in a dose-dependent manner (Figure 4B,C).

(A)

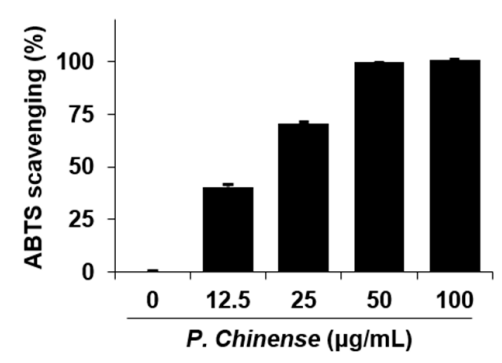

(B)

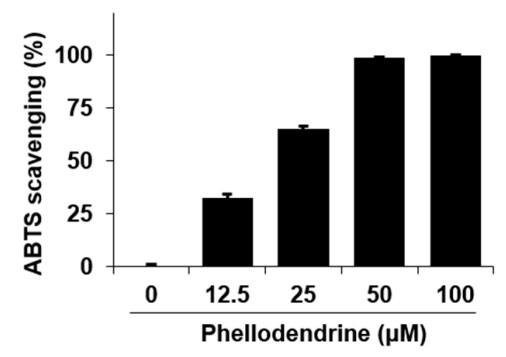

(C)

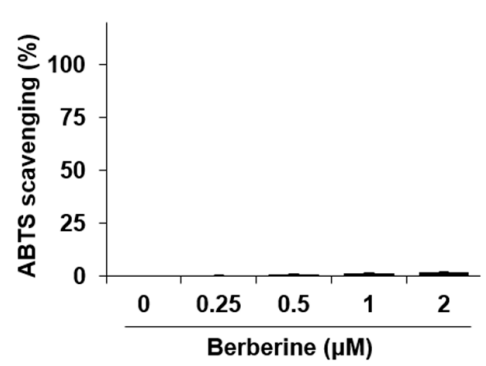

Figure 4. The 2,2'-azino-bis(3-ethylbenzothiazoline-6-sulphonic acid) (ABTS) radical scavenging activity of an ethanol extract of $P$. chinense and its components: (A) ethanol extract of $P$. chinense; (B) phellodendrine; and (C) berberine. ABTS scavenging activities are equal to the percentage inhibition of the ABTS radical. Each value is presented as the mean $\pm \operatorname{SEM}(n=3)$.

\subsection{Neuroprotective Effects of the P. chinense Extract in HT22 Neuronal Cells}

We further confirmed the biological activity of the P. chinense extract on Alzheimer's disease using HT22 murine hippocampal cells. A Cell Counting Kit (CCK) assay was performed to examine the viability of HT22 cells. Cells were treated with various concentrations of $P$. chinense for $24 \mathrm{~h}$. Treatment with $P$. chinense extract had no significant effect on cell viability at a concentration $\leq 100 \mu \mathrm{g} / \mathrm{mL}$ (Figure 5A).

Subsequently, the release of lactose dehydrogenase (LDH) was measured to investigate whether the $P$. chinense extract has a protective effect in neuronal cells. HT22 cells were exposed to hydrogen peroxide $\left(\mathrm{H}_{2} \mathrm{O}_{2}\right)$ with or without the $P$. chinense extract. $\mathrm{H}_{2} \mathrm{O}_{2}$ administration significantly increased LDH release compared with the untreated control. In contrast, the $P$. chinense extract significantly reduced the levels of $\mathrm{LDH}$ in $\mathrm{H}_{2} \mathrm{O}_{2}$-treated $\mathrm{HT} 22$ cells compared with $\mathrm{H}_{2} \mathrm{O}_{2}$ alone (Figure 5B). 
(A)

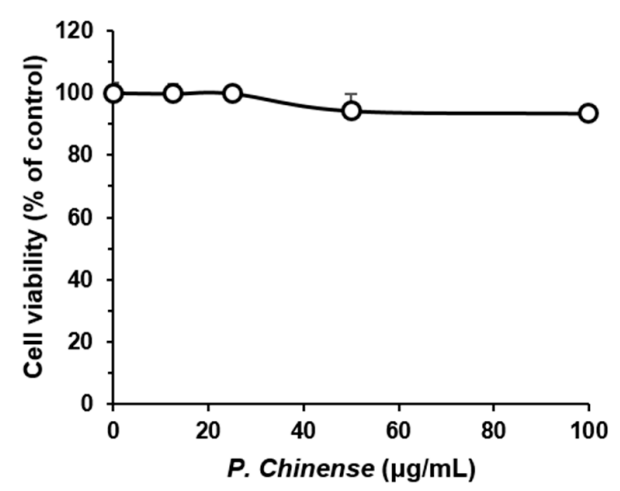

(B)

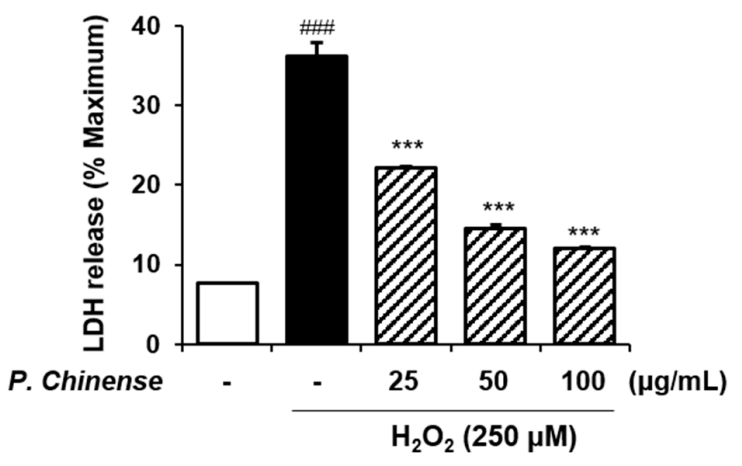

Figure 5. Neuroprotective effect of an ethanol extract of $P$. chinense in HT22 hippocampal cells. (A) Cells were seeded in 96-well plates and treated with various concentrations (0, 12.5, 25, 50 or $100 \mu \mathrm{g} / \mathrm{mL}$ ) of $P$. chinense for $24 \mathrm{~h}$. Cell viability was assessed using the Cell Counting Kit (CCK)-8 assay; (B) Neuroprotection was tested using the lactose dehydrogenase (LDH) release assay. As an indicator of cell disruption, LDH release from the cells was measured in supernatants and cell lysates. The results are expressed as the mean \pm SEM of three independent experiments. $\# \# \#$ $p<0.001$ vs. vehicle control cells; ${ }^{* * *} p<0.001$ vs. $\mathrm{H}_{2} \mathrm{O}_{2}$-treated cells.

\section{Discussion}

The traditional medicinal herb $P$. chinense has been used to reduce heat and fever and to release toxins in Asian countries, including Korea, China, and Japan [10]. Here, we demonstrated that an ethanol extract of $P$. chinense had a potent effect on Alzheimer's disease-related in vitro bioevents, such as AChE activation, antioxidation, and the protection against neuronal cell damage. We also investigated the concentration of the chemical components of $P$. chinense and its biological activities regarding Alzheimer's disease-related factors.

To develop a quality control for $P$. chinense, a quantitative analysis of its chemical constituents, including phellodendrine and berberine, was performed using HPLC-PDA. As a result, the contents of phellodendrine and berberine were determined to be $22.255 \pm 0.123 \mathrm{mg} / \mathrm{g}$ and $269.651 \pm 1.257 \mathrm{mg} / \mathrm{g}$, respectively. Phellodendrine has been reported to have antioxidant and anti-inflammatory properties [16], and to act as an immunosuppressor $[17,18]$. Many studies have reported the biological and clinical efficacies of berberine from several different herbal plants, such as Berberis vulgaris, Hydrastis canadensis, Xanthorhiza simplicissima, P. amurense, and Coptis chinensis. Berberine is known to be a potential therapeutic agent for diabetes [19], hyperlipidemia [20], and cancers [21-23]. Recently, Kaufmann et al. reported the anti-Alzheimer's disease effect of a combined treatment with berberine, coptisine, and palmatine, by targeting AChE activity [24]. However, those authors focused on the synergistic effect of the three alkaloids and evaluated only AChE activity as a biological marker of Alzheimer's disease. 
$\mathrm{AChE}$ is an enzyme that is present in the central nervous system and hydrolyzes acetylcholine and acetate, mainly functioning as a neurotransmitter. Currently, AChE inhibitors are the gold-standard treatment for Alzheimer's disease [25]. For example, donepezil, rivastigmine, and galantamine are the major therapies approved by the US Food and Drug Administration (FDA) and the European Medicines Agency for the symptomatic treatment of Alzheimer's disease [26]. However, these agents are only able to alleviate minor symptomatic problems and are not curative. They also cause serious side effects, such as bradycardia, hypotension, hypersecretion, bronchoconstriction, gastrointestinal tract hypermotility, and decreased intraocular pressure. Therefore, a new drug discovery for Alzheimer's disease is required, with more attention to the AChE inhibition and less side effects. Many papers have reported the potential of herbal plants as AChE inhibitors to overcome the problems of synthetic drugs. For instance, Saleem et al. reported the significant inhibitory activity of Jatropha gossypyfolia leaves on the AChE [27]. Yang et al. reported potent AChE inhibitors isolated from seeds of Peganum harmala [28]. In our study, treatment with the herbal plant $P$. chinense ethanol extract led to a dramatic increase in AChE activity inhibition. In contrast, no significant effect was observed on amyloid- $\beta$ aggregation, which is another key characteristic of Alzheimer's disease [29]. The two standard components of P. chinense also increased the inhibition of AChE in a dose-dependent manner.

Oxidative stress plays a critical role in the pathogenesis of Alzheimer's disease [30]. A large number of herbal medicines or their phytochemicals have been reported to have strong antioxidant activities by scavenging free radicals, thus acting as anti-Alzheimer's disease drugs [31,32]. We conducted an ABTS radical scavenging activity assay to assess the antioxidant effects of the $P$. chinense extract and of its two chemical components. As expected, the P. chinense extract dose-dependently increased the ABTS radical scavenging activity. However, scavenging activity was detected for phellodendrine, but not for berberine. To date, several articles have reported the free radical scavenging activity of berberine extracted from various herbal plants [33-35]. In comparison with those reports, we used lower concentrations of berberine $(\leq 2 \mu \mathrm{M}=0.67 \mu \mathrm{g} / \mathrm{mL})$ because of its cytotoxicity against neuronal cells at $\geq 2 \mu \mathrm{M}$ (data not shown). According to Shirwaikar et al., the ABTS scavenging activity of berberine occurred in a dose-dependent manner, with maximum activity at $512 \mu \mathrm{g} / \mathrm{mL}$ and minimum activity at $2 \mu \mathrm{g} / \mathrm{mL}\left(\mathrm{IC}_{50}=38.7 \mu \mathrm{g} / \mathrm{mL}\right)$ [36]. Thus, phellodendrine, rather than berberine, may be considered as the active compound from $P$. chinense with anti-Alzheimer's activity, although its amount in the P. chinense extract was lower than that of berberine.

The clinical symptoms of Alzheimer's disease are thought to be associated with the degree of neuronal loss in the hippocampus and cerebral neocortex [36]. Therefore, we further confirmed the anti-Alzheimer's activity of $P$. chinense by analyzing its neuroprotective effect. Neuronal cell damage was induced by exposing HT22 hippocampal cells to $\mathrm{H}_{2} \mathrm{O}_{2}$ and measuring the release of LDH. LDH is an enzyme that catalyzes the conversion of lactate to pyruvate. It is found in living cells and released from damaged tissues or cells. Treatment with $\mathrm{H}_{2} \mathrm{O}_{2}$, which is an inducer of oxidative stress in neuronal cells $[37,38]$, significantly stimulated LDH release, while the concurrent administration of $\mathrm{H}_{2} \mathrm{O}_{2}$ and the $P$. chinense extract significantly reduced the $\mathrm{H}_{2} \mathrm{O}_{2}$-mediated LDH levels. These results suggest that $P$. chinense has the ability to protect against neuronal cell death.

In summary, our investigation successfully established an HPLC analytical method for the quantification of the two standard components of $P$. chinense and will be helpful for the quality control of $P$. chinense. Furthermore, our findings suggest the potential of phellodendrine as an active component of $P$. chinense for targeting Alzheimer's disease. Additional experiments will be required to verify the anti-Alzheimer's activities of $P$. chinense and phellodendrine and to understand their regulatory mechanisms using in vitro and in vivo models of Alzheimer's disease. 


\section{Materials and Methods}

\subsection{Plant Material}

The bark of Phellodendron chinense used in this study was purchased from the Kwangmyungdang herbal market (Ulsan, Korea) and identified by Dr. Goya Choi, K-herb Research Center, Korea Institute of Oriental Medicine, Daejeon, Korea. A voucher specimen (Phch5-LE) has been deposited at the Herbal Medicine Research Division, Korea Institute of Oriental Medicine.

\subsection{Chemicals and Reagents}

The standard components, phellodendrine and berberine, were purchased from Biopurify Phytochemicals Ltd. (Chengdu, China) and ChemFaces Biochemical Co., Ltd. (Wuhan, China), respectively. The chemical structures of the standard components are shown in Figure 1. The purity of these standard components was $\geq 98.0 \%$, as assessed using HPLC. The HPLC-grade solvents, acetonitrile and water were purchased from J. T. Baker Chemical Co. (Phillipsburg, NJ, USA), and the analytical-grade reagent trifluoroacetic acid (TFA) was purchased from Sigma-Aldrich (St. Louis, MO, USA).

\subsection{Apparatus and Chromatographic Conditions}

Quantitative analysis was conducted using a Waters Alliance e2695 system (Waters Corp., Milford, MA, USA) equipped with a pump, degasser, column oven, autosampler, and photodiode array detector (\#2998; Waters Corp.). The data were acquired and processed using Empower software (version 3; Waters Corp.). The chromatographic separation of the two standard components was carried out at room temperature using Luna $C_{18}$ analytical columns $(250 \mathrm{~mm} \times 4.6 \mathrm{~mm}, 5 \mu \mathrm{m})$ supplied by Phenomenex (Torrance, CA, USA), with a gradient solvent system of acetonitrile and water. The UV wavelengths used for detection were $200 \mathrm{~nm}$ for phellodendrine and $226 \mathrm{~nm}$ for berberine. The flow rate was $1.0 \mathrm{~mL} / \mathrm{min}$ and the injection volume was $10 \mu \mathrm{L}$.

\subsection{Preparation of Standard Solutions}

The two components were weighed accurately, dissolved in methanol at $1.0 \mathrm{mg} / \mathrm{mL}$, and stored at $<4{ }^{\circ} \mathrm{C}$. Each stock solution was used for quantitative analysis after serial dilution with methanol.

\subsection{Preparation of Sample Solutions}

The dried bark of $P$. chinense (45 g) was extracted twice with $70 \%$ ethanol $(270 \mathrm{~mL})$ by refluxing for $2 \mathrm{~h}$. The extracted solution was filtered through a filter paper $(5 \mu \mathrm{m})$ and evaporated using a rotary evaporator (EYELA N-1000; Rikakikai Co., Tokyo, Japan) under vacuum to give a powdered $70 \%$ ethanol extract $(9.03 \mathrm{~g})$. The yield of $P$. chinense extract was $20 \%$. For quantitative analysis, the powdered $70 \%$ ethanol extract of $P$. chinense was weighed accurately and dissolved in methanol at a concentration of $2.5 \mathrm{mg} / \mathrm{mL}$. The sample solution was filtered through a syringe filter $(0.45 \mu \mathrm{m})$ before HPLC analysis.

\subsection{Calibration Curves and Limits of Detection and Quantification}

The calibration curves of the components were obtained by assessment of the peak areas of the standard solutions at five different concentrations. The tested concentration ranges were 12.5-200 $\mu \mathrm{g} / \mathrm{mL}$ for phellodendrine and 62.5-1000 $\mu \mathrm{g} / \mathrm{mL}$ for berberine. The LOD and LOQ for the two standard components were calculated using the slope of the calibration curve and the standard deviation (SD) of the intercept, as follows:

$\mathrm{LOD}=3.3 \times(\mathrm{SD}$ of the response/slope of the calibration curve $)$

$\mathrm{LOQ}=10 \times(\mathrm{SD}$ of the response/slope of the calibration curve $)$. 


\subsection{In Vitro AChE Activity Assay}

In vitro AChE activity was assessed according to a protocol based on Ellman's colorimetric method [39], with modifications using a Acetylcholinesterase Assay Kit (Abcam, Cambridge, UK). Stock solution of 70\% ethanol extract from $P$. chinense was dissolved in DMSO at a concentration of $100 \mathrm{mg} / \mathrm{mL}$. Preparation of 70\% ethanol extract from P. chinense was addressed above in Section 4.5. Assay samples were prepared by diluting in $0.1 \mathrm{M}$ sodium phosphate buffer ( $\mathrm{pH} \mathrm{8.0).} \mathrm{In} \mathrm{detail,}$ the $70 \%$ ethanol extract of $P$. chinense at a concentration of $100 \mathrm{mg} / \mathrm{mL}$ was diluted in $0.1 \mathrm{M}$ sodium phosphate buffer ( $\mathrm{pH} 8.0$ ) to a final concentration of $100,50,25$, and $12.5 \mu \mathrm{g} / \mathrm{mL}$ of serial dilutions. The two standard compounds phellodendrine (100 mM in DMSO) and berberine (1 mM in DMSO) were dissolved in 0.1 M sodium phosphate buffer ( $\mathrm{pH} 8.0$ ) to a final concentration of 100, 50, 25 and $12.5 \mu \mathrm{M}$, and $1,0.5,0.25$ and $0.125 \mu \mathrm{M}$ of serial dilutions, respectively. The AChE stock solution was prepared by dissolving in $0.1 \%$ bovine serum albumin $/ \mathrm{H}_{2} \mathrm{O}$ at $25 \mathrm{U} / \mathrm{mL}$ and dissolved in $0.1 \mathrm{M}$ sodium phosphate buffer ( $\mathrm{pH} 7.3$, assay buffer), to a final concentration of $35.2 \mathrm{mU} / \mathrm{mL}$, before the assay. The substrates acetylthiocholine iodide and 5,5'-dithiobis-2-nitrobenzoic acid (DTNB) were dissolved in $\mathrm{H}_{2} \mathrm{O}$ and assay buffer, respectively, at $10 \mathrm{mM}$, and both solutions were diluted 20-fold in assay buffer to a final concentration of $0.5 \mathrm{mM}$. In detail, $0.6 \mathrm{~mL}$ of $\mathrm{H}_{2} \mathrm{O}$ and assay buffer were added in acetylthiocholine iodide and DTNB, respectively, to make $10 \mathrm{mM}$ stock solution. For assays, $0.25 \mathrm{~mL}$ of each $10 \mathrm{mM}$ acetylthiocholine iodide and DTNB was mixed in $4.75 \mathrm{~mL}$ of assay buffer to a final concentration of $0.5 \mathrm{mM}$ and used as the reaction mixture. For the enzymatic reaction in 96-well plates, $50 \mu \mathrm{L}$ of the sample solution and $50 \mu \mathrm{L}$ of the reaction mixture were mixed and preincubated for $10 \mathrm{~min}$ at room temperature. The $10 \mu \mathrm{L}$ of AChE solution was then added to the initial mixture to start the reaction, which was carried out for $1 \mathrm{~h}$ at room temperature. The absorbance was measured at $412 \mathrm{~nm}$ using an Epoch microplate spectrophotometer (Bio-Tek Instruments, Winooski, VT, USA). The inhibition of the activity of AChE was calculated by comparing the rate of reaction of the sample to that of the blank. All experiments were performed in triplicate, and the percentage of inhibition against the AChE activity was calculated according to the following equation:

$$
\text { AChE activity inhibition }(\%)=1-\frac{S-S^{\prime}}{C-C^{\prime}} \times 100
$$

S: samples (sample solution, assay buffer with DTNB, substrate, and enzyme)

$S^{\prime}$ : samples (sample solution, assay buffer with DTNB and substrate, without enzyme)

C: control (0.1 M sodium phosphate buffer ( $\mathrm{pH} 8.0)$, assay buffer with DTNB, substrate, and enzyme) $\mathrm{C}^{\prime}$ : control (0.1 M sodium phosphate buffer ( $\left.\mathrm{pH} 8.0\right)$, assay buffer with DTNB and substrate, without enzyme)

\subsection{In Vitro Amyloid- $\beta$ Aggregation Assay}

Amyloid- $\beta$ (1-42) aggregation was measured using the SensoLyte ${ }^{\circledR}$ Thioflavin T $\beta$-Amyloid aggregation kit (AnaSpec, Fremont, CA, USA), according to the manufacturer's instructions. The assay is based on the property of the Thioflavin T dye, the fluorescence of which increases when it is bound to aggregates of amyloid- $\beta$ (1-42) peptides. Briefly, Thioflavin T was dissolved in assay buffer (50 mM Tris/150 mM NaCl (pH = 7.2), $20 \mathrm{mM}$ HEPES/150 mM NaCl (pH = 7.2), $10 \mathrm{mM}$ phosphate/150 mM $\mathrm{NaCl}$ ) and used at a concentration of $100 \mu \mathrm{M}$. Samples were dissolved in assay buffer and used at a final concentration of $100 \mu \mathrm{g} / \mathrm{mL}$. To measure the inhibition of amyloid- $\beta$ (1-42) aggregation in 96-well black microplates, $5 \mu \mathrm{L}$ of the sample and $85 \mu \mathrm{L}$ of amyloid- $\beta$ (1-42) were mixed, followed by the addition of $10 \mu \mathrm{L}$ of Thioflavin T. Thioflavin T fluorescence was measured at intervals of $20 \mathrm{~min}$ for $2 \mathrm{~h}$, with an excitation wavelength $\left(\lambda_{\mathrm{ex}}\right)$ of $440 \mathrm{~nm}$ and an emission wavelength $\left(\lambda_{\mathrm{em}}\right)$ of $485 \mathrm{~nm}$ using a SpectraMax i3 Multi-Mode Detection Platform (Molecular Devices, Sunnyvale, CA, USA). This gave seven readings for each well sample. All fluorescence readings are expressed in relative fluorescence units. Morin was used as a positive control. Experiments were performed in triplicate and averaged, 
and the percentage of inhibition of amyloid- $\beta$ aggregation was calculated according to the following equation:

$$
\text { Amyloid }-\beta \text { aggregation inhibition }(\%)=1-\frac{S-S^{\prime}}{C-C^{\prime}} \times 100
$$

S: samples (sample solution, assay buffer with ThT, amyloid- $\beta$ solution)

$S^{\prime}$ : samples (sample solution, assay buffer with ThT, without amyloid- $\beta$ solution)

C: control (assay buffer with ThT, amyloid- $\beta$ solution)

$C^{\prime}$ : control (assay buffer with ThT, without amyloid- $\beta$ solution)

\subsection{ABTS Radical Scavenging Activity}

The 2,2'-Azino-bis(3-ethylbenzothiazoline-6-sulphonic acid) (ABTS) radical cations were produced by reacting a $7 \mathrm{mM}$ ABTS solution with $2.45 \mathrm{mM}$ potassium persulfate in the dark at room temperature for $16 \mathrm{~h}$. The absorbance of the reactant was later adjusted to 0.7 at a wavelength of $734 \mathrm{~nm}$. Aliquots of $P$. chinense extract solution $(100 \mu \mathrm{L})$ at various concentrations were mixed with $100 \mu \mathrm{L}$ of $\mathrm{ABTS}^{\bullet+}$ solution. The reaction mixture was incubated for $5 \mathrm{~min}$ in the dark at room temperature. The absorbance of the resulting solution was measured at $734 \mathrm{~nm}$ using an Epoch microplate spectrophotometer (Bio-Tek Instruments). The radical scavenging capacity of the P. chinense extract-treated samples was calculated using the following equation:

$$
\text { Scavenging activity }(\%)=\frac{1-\text { Absorbance of } P \text {. chinense extract }- \text { treated sample }}{\text { Absorbance of untreated sample }} \times 100
$$

\subsection{CCK Assay}

The HT22 cells were maintained in Dulbecco's modified Eagle's medium (Hyclone/Thermo, Rockford, IL, USA) supplemented with $10 \%$ fetal bovine serum (Hyclone/Thermo) and penicillin/streptomycin in $5 \% \mathrm{CO}_{2}$ at $37^{\circ} \mathrm{C}$.

To determine the nontoxic concentration of the P. chinense extract in HT22 cells, a CCK assay was performed using a CCK-8 assay kit (Dojindo, Kumamoto, Japan). Cells were plated in 96-well microplates at a density of $5 \times 10^{3}$ cells / well and treated with various concentrations $(0,12.5,25$, 50 and $100 \mu \mathrm{g} / \mathrm{mL}$ ) of the P. chinense extract for $24 \mathrm{~h}$. The CCK-8 solution was added and the cells were incubated for $4 \mathrm{~h}$. Absorbance was read at $450 \mathrm{~nm}$ on an Epoch microplate spectrophotometer (Bio-Tek Instruments). Cell viability was calculated using the following equation:

$$
\text { Cell viability }(\%)=\frac{\text { Mean OD in } P \text {. chinense extract }- \text { treated cells }}{\text { Mean OD in untreated cells }} \times 100
$$

\subsection{LDH Release Assay}

To determine the neuroprotective effect of the P. chinense extract, the release of LDH was measured in $\mathrm{H}_{2} \mathrm{O}_{2}$-damaged HT22 cells using the CytoTox 96 nonradioactive cytotoxicity assay kit (Promega, Madison, WI, USA). Cells were lysed to induce maximal LDH release, and supernatants were collected to measure experimental LDH release. Cell lysates or supernatants were reacted with substrate mixture at room temperature for $30 \mathrm{~min}$ in the dark. After adding the stop solution, absorbance at $490 \mathrm{~nm}$ was measured on an Epoch microplate spectrophotometer (Bio-Tek Instruments). The cytotoxicity of the P. chinense extract was calculated using the following formula:

$$
\text { Cytotoxicity }(\%)=\frac{\text { Experimental LDH release }}{\text { Maximum LDH release }} \times 100
$$




\subsection{Statistical Analysis}

The data are expressed as the mean \pm SEM. Data were analyzed using one-way analysis of variance and Dunnett's multiple comparisons test. $p<0.05$ was considered significant.

Acknowledgments: This study was supported by a research grant (K17293) from the Korea Institute of Oriental Medicine (KIOM).

Author Contributions: Y.J.K., H.-S.L., and S.-J.J. participated in the design of the study data analyses and manuscript preparation. Y.J.K. and J.L. conducted P. chinense extract and analysis of two constituents in P. chinense extract using HPLC. H.-S.L., Y.K., B.-Y.K. and S.-J.J. conducted the biological examination of in vitro. All authors read and approved the final manuscript.

Conflicts of Interest: The authors declare no conflict of interest.

\section{References}

1. World Health Organization. Dementia Fact Sheet N 362 ; World Health Organization: Geneva, Switzerland, 2015.

2. Burns, A.; Iliffe, S. Alzheimer's disease. BMJ 2009, 338. [CrossRef] [PubMed]

3. Ballard, C.; Gauthier, S.; Corbett, A.; Brayne, C.; Aarsland, D.; Jones, E. Alzheimer's disease. Lancet 2011, 377, 1019-1031. [CrossRef]

4. World Health Organization. The Top 10 Causes of Death Fact Sheet; World Health Organization: Geneva, Switzerland, 2017.

5. Bartus, R.T. On neurodegenerative diseases, models, and treatment strategies: Lessons learned and lessons forgotten a generation following the cholinergic hypothesis. Exp. Neurol. 2000, 163, 495-529. [CrossRef] [PubMed]

6. Selkoe, D.J.; Hardy, J. The amyloid hypothesis of Alzheimer's disease at 25 years. EMBO Mol. Med. 2016, 8, 595-608. [CrossRef] [PubMed]

7. Qiu, T.Y.; Chang, D.L.; Tang, J.W. Wood anatomical properties of Phellodendron chinense var. glabriusculum. J. Northeast For. Univ. 2006, 34, 36-38.

8. Yan, C.; Wang, Y.; Hao, X.J. Triterpenes from the fruits of Phellodendron chinense Schneid var. glabriusculum Schneid. Chin. J. Nat. Med. 2009, 7, 31-33. [CrossRef]

9. Park, S.D.; Lai, Y.S.; Kim, C.H. Immunopontentiating and antitumor activities of the purified polysaccharides from Phellodendron chinese Schneid. Life Sci. 2004, 75, 2621-2632. [CrossRef] [PubMed]

10. Yan, C.; Zhang, Y.D.; Wang, X.H.; Geng, S.D.; Wang, T.Y.; Sun, M.; Liang, W.; Zhang, W.Q.; Zhang, X.D.; Luo, H. Tirucallane-type triterpenoids from the fruits of Phellodendron chinense Schneid and their cytotoxic activities. Fitoterapia 2016, 113, 132-138. [CrossRef] [PubMed]

11. Zheng, L.; Sidike, G.M.; Zhang, Y.M. Study on antitumor effect of wutousan. Zhong Yao Cai 2013, 36, 1301-1304. [PubMed]

12. Xian, Y.F.; Mao, Q.Q.; Ip, S.P.; Lin, Z.X.; Che, C.T. Comparison on the anti-inflammatory effect of Cortex Phellodendri chinensis and Cortex Phellodendri amurensis in 12-O-tetradecanoyl-phorbol-13-acetate-induced ear edema in mice. J. Ethnopharmacol. 2011, 137, 1425-1430. [CrossRef] [PubMed]

13. Zhang, Q.; Li, Y.; Chen, L. Effect of berberine in treating type 2 diabetes mellitus and complications and its relevant mechanisms. Zhongguo Zhong Yao Za Zhi 2015, 40, 1660-1665. [PubMed]

14. Ye, L.; Qian, J.; Jin, S.; Zuo, S.; Mei, H.; Ma, S. Algicidal effects of four Chinese herb extracts on bloom-forming Microcystis aeruginosa and Chlorella pyrenoidosa. Environ. Technol. 2014, 35, 1150-1156. [CrossRef] [PubMed]

15. Xian, Y.F.; Lin, Z.X.; Ip, S.P.; Su, Z.R.; Chen, J.N.; Lai, X.P. Comparison of the neuroprotective effect of Cortex Phellodendri chinensis and Cortex Phellodendri amurensis against beta-amyloid-induced neurotoxicity in PC12 cells. Phytomedicine 2013, 20, 187-193. [CrossRef] [PubMed]

16. Li, L.; Huang, T.; Tian, C.; Xiao, Y.; Kou, S.; Zhou, X.; Liu, S.; Ye, X.; Li, X. The defensive effect of phellodendrine against AAPH-induced oxidative stress through regulating the AKT/NF-kappaB pathway in zebrafish embryos. Life Sci. 2016, 157, 97-106. [CrossRef] [PubMed]

17. Mori, H.; Fuchigami, M.; Inoue, N.; Nagai, H.; Koda, A.; Nishioka, I. Principle of the bark of Phellodendron amurense to suppress the cellular immune response. Planta Med. 1994, 60, 445-449. [CrossRef] [PubMed] 
18. Mori, H.; Fuchigami, M.; Inoue, N.; Nagai, H.; Koda, A.; Nishioka, I.; Meguro, K. Principle of the bark of Phellodendron amurense to suppress the cellular immune response: Effect of phellodendrine on cellular and humoral immune responses. Planta Med. 1995, 61, 45-49. [CrossRef] [PubMed]

19. Dong, H.; Wang, N.; Zhao, L.; Lu, F. Berberine in the treatment of type 2 diabetes mellitus: A systemic review and meta-analysis. Evid. Based Complement. Altern. Med. 2012, 2012, 591654. [CrossRef] [PubMed]

20. Wang, Y.; Yi, X.; Ghanam, K.; Zhang, S.; Zhao, T.; Zhu, X. Berberine decreases cholesterol levels in rats through multiple mechanisms, including inhibition of cholesterol absorption. Metab. Clin. Exp. 2014, 63, 1167-1177. [CrossRef] [PubMed]

21. Wang, H.Y.; Yu, H.Z.; Huang, S.M.; Zheng, Y.L. p53, Bcl-2 and cox-2 are involved in berberine hydrochloride-induced apoptosis of HeLa229 cells. Mol. Med. Rep. 2016, 14, 3855-3861. [PubMed]

22. Wang, N.; Wang, X.; Tan, H.Y.; Li, S.; Tsang, C.M.; Tsao, S.W.; Feng, Y. Berberine suppresses cyclin D1 expression through proteasomal degradation in human hepatoma cells. Int. J. Mol. Sci. 2016, 17, 1899. [CrossRef] [PubMed]

23. Zhuo, Y.; Chen, Q.; Chen, B.; Zhan, X.; Qin, X.; Huang, J.; Lv, X. Berberine promotes antiproliferative effects of epirubicin in T24 bladder cancer cells by enhancing apoptosis and cell cycle arrest. Int. J. Clin. Pharmacol. Ther. 2017, 55, 32-40. [CrossRef] [PubMed]

24. Kaufmann, D.; Kaur Dogra, A.; Tahrani, A.; Herrmann, F.; Wink, M. Extracts from traditional Chinese medicinal plants inhibit acetylcholinesterase, a known Alzheimer's disease target. Molecules 2016, 21, 1161. [CrossRef] [PubMed]

25. Martorana, A.; Esposito, Z.; Koch, G. Beyond the cholinergic hypothesis: Do current drugs work in Alzheimer's disease? CNS Neurosci. Ther. 2010, 16, 235-245. [CrossRef] [PubMed]

26. Lahiri, D.K.; Farlow, M.R.; Greig, N.H.; Sambamurti, K. Current drug targets for Alzheimer's disease treatment. Drug Dev. Res. 2002, 56, 267-281. [CrossRef]

27. Saleem, H.; Ahmad, I.; Shahid, M.N.; Gill, M.S.; Nadeem, M.F.; Mahmood, W.; Rashid, I. In vitro acetylcholinesterase and butyrylcholinesterase inhibitory potentials of Jatropha gossypifolia plant extracts. Acta Pol. Pharm. 2016, 73, 419-423. [PubMed]

28. Yang, Y.; Cheng, X.; Liu, W.; Chou, G.; Wang, Z.; Wang, C. Potent AChE and BChE inhibitors isolated from seeds of Peganum harmala Linn by a bioassay-guided fractionation. J. Ethnopharmacol. 2015, 168, 279-286. [CrossRef] [PubMed]

29. Sadigh-Eteghad, S.; Sabermarouf, B.; Majdi, A.; Talebi, M.; Farhoudi, M.; Mahmoudi, J. Amyloid-beta: A crucial factor in Alzheimer's disease. Med. Princ. Pract. 2015, 24, 1-10. [CrossRef] [PubMed]

30. Huang, W.J.; Zhang, X.; Chen, W.W. Role of oxidative stress in Alzheimer's disease. Biomed. Rep. 2016, 4, 519-522. [CrossRef] [PubMed]

31. Apetz, N.; Munch, G.; Govindaraghavan, S.; Gyengesi, E. Natural compounds and plant extracts as therapeutics against chronic inflammation in Alzheimer's disease-A translational perspective. CNS Neurol. Disord. Drug Targets 2014, 13, 1175-1191. [CrossRef] [PubMed]

32. Wang, Z.Y.; Liu, J.G.; Li, H.; Yang, H.M. pharmacological effects of active components of Chinese herbal medicine in the treatment of Alzheimer's disease: A review. Am. J. Chin. Med. 2016, 44, 1525-1541. [CrossRef] [PubMed]

33. Abd El-Wahab, A.E.; Ghareeb, D.A.; Sarhan, E.E.; Abu-Serie, M.M.; El Demellawy, M.A. In vitro biological assessment of Berberis vulgaris and its active constituent, berberine: Antioxidants, anti-acetylcholinesterase, anti-diabetic and anticancer effects. BMC Complement. Altern. Med. 2013, 13, 218. [CrossRef] [PubMed]

34. Shirwaikar, A.; Shirwaikar, A.; Rajendran, K.; Punitha, I.S. In vitro antioxidant studies on the benzyl tetra isoquinoline alkaloid berberine. Biol. Pharm. Bull. 2006, 29, 1906-1910. [CrossRef] [PubMed]

35. Jang, M.H.; Kim, H.Y.; Kang, K.S.; Yokozawa, T.; Park, J.H. Hydroxyl radical scavenging activities of isoquinoline alkaloids isolated from Coptis chinensis. Arch. Pharm. Res. 2009, 32, 341-345. [CrossRef] [PubMed]

36. Fukutani, Y.; Cairns, N.J.; Shiozawa, M.; Sasaki, K.; Sudo, S.; Isaki, K.; Lantos, P.L. Neuronal loss and neurofibrillary degeneration in the hippocampal cortex in late-onset sporadic Alzheimer's disease. Psychiatry Clin. Neurosci. 2000, 54, 523-529. [CrossRef] [PubMed]

37. Zhao, Z.Y.; Luan, P.; Huang, S.X.; Xiao, S.H.; Zhao, J.; Zhang, B.; Gu, B.B.; Pi, R.B.; Liu, J. Edaravone protects HT22 neurons from $\mathrm{H}_{2} \mathrm{O}_{2}$-induced apoptosis by inhibiting the MAPK signaling pathway. CNS Neurosci. Ther. 2013, 19, 163-169. [CrossRef] [PubMed] 
38. Vedder, H.; Teepker, M.; Fischer, S.; Krieg, J.C. Characterization of the neuroprotective effects of estrogens on hydrogen peroxide-induced cell death in hippocampal HT22 cells: Time and dose-dependency. Exp. Clin. Endocrinol. Diabetes 2000, 108, 120-127. [CrossRef] [PubMed]

39. Ellman, G.L.; Courtney, K.D.; Andres, V., Jr.; Feather-Stone, R.M. A new and rapid colorimetric determination of acetylcholinesterase activity. Biochem. Pharmacol. 1961, 7, 88-95. [CrossRef]

Sample Availability: Samples of the compounds phellodendrine and berberine are commercially available.

(C) 2017 by the authors. Licensee MDPI, Basel, Switzerland. This article is an open access article distributed under the terms and conditions of the Creative Commons Attribution (CC BY) license (http:/ / creativecommons.org/licenses/by/4.0/). 